\title{
Tsetse fly distribution and occurrence of Trypanosoma species among cattle and goats around Queen Elizabeth National park, Uganda
}

\author{
Mallion Kangume \\ Africa Centers for Disease Control and Prevention, AU Commission \\ Denis Muhangi \\ College of Veterinary Medicine Makerere University \\ Joseph Byaruhanga \\ College of Veterinary medicine Animal Resources and Biosecurity \\ Aggrey Agaba \\ Africa One health University Network \\ Joachim Sserunkuma \\ Makerere University College of Veterinary Medicine Animal Resources and Biosecurity ences \\ Stallon Justus Kisembo \\ Africa One Health University Network \\ Paul Bogere \\ Busitema University

\section{Patrick Vudriko} \\ Makerere University COllege of Veterinary Medicine Animal Resources and Biosecurity \\ Innocent Bidason Rwego ( $\square$ rwegovet@gmail.com ) \\ Makerere University College of Biosecurity Animal Resources and Veterinary medicine https://orcid.org/0000-0003-1274- \\ 7788
}

\section{Research article}

Keywords: Glossina species, Trypanosoma species; co-infections; neglected tropical diseases

Posted Date: June 30th, 2020

DOI: https://doi.org/10.21203/rs.3.rs-32266/v1

License: (c) (i) This work is licensed under a Creative Commons Attribution 4.0 International License. Read Full License 


\section{Abstract \\ Background}

African Animal Trypanosomiasis (AAT) is an infectious disease of economic and public health importance hindering agricultural productivity in Sub-Saharan Africa. The current study aimed at providing baseline information on tsetse fly distribution and occurrence of Trypanosoma species in cattle and goats within and around Queen Elizabeth National Park (QENP), in western Uganda. A minimal entomological survey was conducted in April 2017 while blood samples collected from cattle $(n=576)$ and goats $(n=319)$ in June 2015 and May 2017 were subjected to microscopy and Polymerase Chain Reaction (PCR) to determine the occurrence of trypanosome species.

\section{Results}

Glossina pallidipes and G. fuscipes were the only tsetse fly species trapped in the study area with apparent density of 20.6. The overall prevalence of Trypanosoma spp. in cattle and goats was 38.9\% and $37 \%$ respectively for samples collected in 2015 while the prevalence of Trypanosome spp in cattle samples collected in 2017 was $38 \%$. In 2015 , T. brucei was the highest prevalent trypanosome in both cattle (23\%) and goats $(18.8 \%)$. In both cattle and goats, a mixed infection of $T$. brucei $+T$. congolense was most encountered with prevalence of $4.8 \%$ and $4.1 \%$ in cattle and goats, respectively. In goats a mixed infection of $T$. brucei+ T. congolense $+T$. vivax was higher $(2.8 \%)$ than in cattle $(2.4 \%)$. In 2017 , in cattle $(n=250)$, the prevalence for T. congolense was $32.4 \%$, T. vivax was $6.8 \%$ and T. brucei was $6.4 \%$. A co-infection of $T$. brucei and $T$. congolense was most prevalent (7.4\%). Only $3.2 \%$ of the cattle were co-infected with all the three Trypanosome species.

\section{Conclusions}

Current findings show that there are two types of Tsetse fly specie, s important in transmission of AAT. Presence of these parasites in goats shows that they also play a key role in epidemiology of the disease and control efforts should aim also involve goat farmers.

\section{Background}

African trypanosomiasis is an infectious disease of economic and public health importance that affects both humans and livestock, negatively affecting food production and economic growth in most parts of the world, especially sub-Saharan Africa. Animal African Trypanasomiais (AAT), or Nagana, is a wide-spread disease in sub-Saharan Africa that affects Agriculture (1-3). Tsetse flies play a big role in the transmission and spread of AAT among the various domestic and wild animals. In Uganda, over $70 \%$ of land is estimated to be infested with tsetse flies with approximately $60 \%$ of livestock at risk of AAT $(4,5)$. The main sub-species of tsetse flies documented in Uganda are Glossina fuscipes and G. pallidipes (4). Glossina fuscipes is the most dominant species around the Lake Victoria basin, Eastern Uganda and Northern part of the country $(4,6)$. Queen Elizabeth National park (QENP) is historically known to be infested with tsetse flies. However, there is no recent study that has been conducted within and around QENP to ascertain the distribution of different species of tsetse fly especially at the livestock-wildlife interface.

In humans, the disease is known as sleeping sickness or Human African Trypanosomiasis (HAT) while in animals it is called Nagana or AAT (6-9). A range of wildlife serve as reservoirs of infection in domestic animals and humans (5). Trypanosomes, the causative agents of the disease are vectored by tsetse fly of the genus Glossina and their distribution coincides with that of their vector $(3,7,8)$. Trypanosomes are parasites that cause trypanosomiasis in both humans and livestock posing a serious threat to agriculture and hindering use of millions of square kilometres of productive in sub-saharan Africa including Uganda $(1,3,8,10-12)$. Areas infested with tsetse flies are faced with food insecurity because of the millions of heads of cattle and other livestock species that are at risk. For instance, it is estimated that not less than three million livestock die each 
year due to presence of Tsetse flies and Trypanosoma spp that have led to reduced calving, reduction in milk yield, decreased numbers of livestock and reduced work efficiency in draught animals (13). Factors such as interaction between tsetse flies, source of vertebrate blood (either from human, livestock and wildlife) and season determine the epidemiology of trypanosomiasis and its impact on livestock production (2).

Studies conducted on trypanosome species in Uganda have been mainly in cattle $(8,10,12)$ and less in goats even though the latter have been shown to play an important role in the distribution and dissemination of the disease $(2,13,14)$. A study conducted by Biryomumaisho et al. (14) in the districts of Kasese, Jinja and Rakai showed the prevalence of trypanosomes to be $7.6 \%$ in cattle and $0.7 \%$ in goats. In QENP ecosystem, there is direct and indirect interaction between humans, livestock, wildlife and humans with animals sometimes sharing common grazing land. Wildlife have been thought to be an important maintenance host for AAT $(1,6)$. The current study looked at the distribution of tsetse fly species and occurrence of Trypanosoma species in communities within and around QENP in cattle and goats. Information is needed to better understand the vector-parasite-host relationship at the wildlife-livestock interface and how this knowledge can be utilized in mitigating the challenge.

\section{Results}

\section{Entomological findings}

A total of 5,003 tsetse flies, G. pallidipes (99.5\%) and G. fuscipes (0.5\%), were captured in communities within and around QENP with other biting flies $(\mathrm{n}=20,237)$ (Table 1). BT traps caught both G. pallidipes $(99.3 \%)$ and G. fuscipes $(0.67 \%)$ while F3 traps caught only G. pallidipes. The biting flies were mainly in the genus of Stomoxys, Tabanids, Muscids, Hymenopteran and Lepidopterans. Stomoxys had the highest number among other biting flies captured (Table 1).

Table 1

Frequency of Tsetse fly species and other biting flies captured in and around QENP

\begin{tabular}{|llll|}
\hline Type of Fly & \multicolumn{2}{l}{ Sex } & \multirow{2}{*}{ Total } \\
\cline { 2 - 3 } & Male & \multicolumn{2}{l}{ Female } \\
\cline { 2 - 3 } & No. (\%) & No. (\%) & \\
\hline Tsetse fly & & \\
\cline { 1 - 3 } G. pallidipes & $368(7 \%)$ & $4,611(93 \%)$ & 4,979 \\
\hline G. fuscipes & $7(29 \%)$ & $17(71 \%)$ & 24 \\
\hline Other Biting flies* & & & 18,310 \\
\hline Stomoxys & - & - & 428 \\
\hline Tabanids & - & - & 278 \\
\hline Muscids & - & - & 117 \\
\hline Hymenopteran & - & - & 14 \\
\hline Lepidopterans & - & - & \\
\hline *No sex determination was done for other biting flies. \\
\hline
\end{tabular}

The computed apparent fly density (FTD), the average number of flies caught per trap per day for the entire surveyed area was 20.6. BT traps caught a total of 3,566 tsetse flies with an average of 63.67 and the FTD of 21.22 tsetse flies per day while F3 caught a total of 1,437 tsetse flies with an average of 62 and FTD of 21 tsetse flies per day (Table 2). 
Table 2

Tsetse fly and Biting flies caught per trap type in different communities around QENP

\begin{tabular}{|c|c|c|c|c|c|c|}
\hline Community Site & Type of Trap & No. of Traps & Tsetse flies/trap & Other biting flies & FTD & Mean $\pm S E^{*}$ \\
\hline \multirow[t]{2}{*}{ Hamukungu } & BT & 10 & 2278 & 282 & \multirow[t]{2}{*}{74.3} & \multirow[t]{2}{*}{$222.87 \pm 50.6$} \\
\hline & F3 & 5 & 1065 & 275 & & \\
\hline \multirow[t]{2}{*}{ Nyakatonzi } & BT & 9 & 1187 & 10068 & \multirow[t]{2}{*}{38.1} & \multirow[t]{2}{*}{$114.23 \pm 40.3$} \\
\hline & F3 & 4 & 298 & 1832 & & \\
\hline \multirow[t]{2}{*}{ Karusandara } & BT & 9 & 31 & 2601 & \multirow[t]{2}{*}{0.9} & \multirow[t]{2}{*}{$2.79 \pm 1.68$} \\
\hline & F3 & 5 & 8 & 2601 & & \\
\hline \multirow[t]{2}{*}{ Muhokya } & BT & 9 & 61 & 447 & \multirow[t]{2}{*}{1.7} & \multirow[t]{2}{*}{$5.08 \pm 2.55$} \\
\hline & F3 & 4 & 5 & 65 & & \\
\hline \multirow[t]{2}{*}{ Ibuga } & BT & 10 & 1 & 1389 & \multirow[t]{2}{*}{0} & \multirow[t]{2}{*}{$0.07 \pm 0.07$} \\
\hline & F3 & 5 & 0 & 393 & & \\
\hline \multirow[t]{2}{*}{ Busunga } & BT & 9 & 8 & 245 & \multirow[t]{2}{*}{2.1} & \multirow[t]{2}{*}{$6.27 \pm 3.756$} \\
\hline & F3 & 2 & 61 & 39 & & \\
\hline Totals & & 81 & 5003 & 20237 & 20.6 & \\
\hline
\end{tabular}

FTD - Apparent fly density; BT and F3 - Types of Tsetse fly traps; Cl - 95\% Cl for mean; *Mean number of Tsetse flies caught in each community (SE - Standard Error)

Hamukungu community had significantly higher numbers $(p=0.001)$ of tsetse flies caught than in the rest of the communities (Table 2). Glossina fuscipes was captured only in Nyakatonzi community along River Nyamugasani that has a marshy riverine forest/woodland vegetation along the river banks (Fig. 1). Figure 1 was developed by authors. the The mean numbers of $G$. pallidipes $(61.5 \pm 14.7)$ captured were significantly higher than that of $G$. fuscipes $(0.3 \pm 0.2)$ in the whole study area ( $p=$ 0.001). There was significantly higher apparent density (FTD) of $G$. pallidipes caught by BT than the $G$. fuscipes captured by the same trap type (F-Statistic $=48.4, p=0.001$ ). There was no $G$. fuscipes trapped by F3 trap but still there was a statistically significant difference for FTD between G. pallidipes and G. fuscipes (F-Statistic $=16.4, p=0.031)$.

Furthermore, the results showed a significant difference in the number of tsetse flies caught in different vegetation types in the study area $(\mathrm{F}-$ Statistic $=8.56, p=0.001)$. Thickets and shrubs had significantly higher numbers of tsetse flies trapped than those trapped in the open savannah grasslands $(D=138.465, p=0.001)$ and marshy riverine woodland $(D=-138.0, p=$ 0.002). However, the difference was not statistically significant with grassland and thickets $(D=98.444, p=0.198)$. There was a significant difference in the number of tsetse flies caught in different vegetation types in the study area (Post hoc Analysis $\mathrm{F}=8.56, p=0.001)$. Marshy riverine woodland had significantly higher number of tsetse flies than open savannah grasslands $(D=271.3, p=0.001)$ and grassland and thickets $(D=231.3, p=0.001)$.

\section{Trypanosomes in cattle and goat blood samples collected in June 2015}

In 2015, a total of 445 blood samples were collected from both cattle and goats with $71.7 \%(n=319)$ of the samples being goats. Three types of Trypanosoma species, namely T. brucei (480 bp), T. congolense (700 bp) and T. vivax (250 bp) were got using PCR (Fig. 2).

$\mathrm{s} 1$ to $\mathrm{s} 11$ correspond to test samples positive for trypanosomes and $\mathrm{N}$ indicates the Negative control while $\mathrm{P} 1$ is positive control for T. brucei, P2; positive control for T. vivax and P3 is positive control for T. congolensis. 700 bp indicates $T$. 
congolensis, 480 bp indicates $T$. brucei and 250 bp represents $T$. vivax. Sample (s6) is positive for both T. congolensis and T. brucei. DNA ladder (100 bp) was used as indicated on the gel above.

The overall prevalence of Trypanosoma spp in cattle and goat blood samples collected in 2015 was $38.9 \%$ and $37 \%$ respectively. However, the prevalence in cattle was not significantly different from that of goats $(\mathrm{F}=1.654, p=0.4870)$. Trypanosoma brucei was the highest prevalent trypanosome in both cattle (23\%) and goats (18.8\%), followed by $T$. congolense while T. vivax was the least prevalent trypanosome in both animal species (Fig. 3).

Figure 3. Prevalence of Trypanosoma spp in cattle and goats in 2015

The proportion of animals with single infection was higher than for mixed infection in both cattle and goats (Fig. 4). In both cattle and goats, a mixed infection of T. brucei+ T. congolense was most encountered with prevalence rates of $4.8 \%(n=$ $6 / 126)$ and $4.1 \%(n=13 / 319)$ in cattle and goats, respectively (Fig. 4). Also, in cattle, a mixed infection of T. brucei $+T$. vivax was higher $(3.2 \%, \mathrm{n}=4 / 126)$ than in goats $(0.6 \%, \mathrm{n}=2 / 319)$ whereas in goats a mixed infection of $T$. brucei+ T. congolense+ T. vivax was higher $(2.8 \%, \mathrm{n}=9 / 319)$ than in cattle $(2.4 \%, \mathrm{n}=3 / 126)$ (Fig. 4$)$.

Kashaka landing site $(50 \%, n=25 / 50)$ had the highest Trypanosoma infection rates followed by Kisenyi landing site (43.9\%), Rwenshama (33.1\%) and lowest in Kirugu sub-county (32.6\%). While the prevalence was high in Kashaka fish landing site (Table 3$)$, the difference compared to other areas was not statistically significant $(p=0.106)$. Cattle in Nyakatonzi community had a trypanosome prevalence of $38.9 \%$.

More males among cattle were observed to have higher trypanosome prevalence (47.8\%) than female (36.9\%). On the contrary, female goats (37.8\%) had a higher prevalence of trypanosomes than the males (33.3\%) (Table 3). However, in as much as the prevalence were different, these differences were not statistically significant in both sexes (Cattle: F [36.9, 47.8] = 2.76, $p=0.245]$; Goats $[\mathrm{F}(37.8,33.3)=1.95, p=0.143])$. The prevalence of trypanosomes among cattle was higher in adults $(44.3 \%, n=31 / 70)$ than in sub-adults $(32.1 \%, n=18 / 56)$. However, the difference wasn't statistically significant at $p>0.05(F=$ $2.62, p=0.094)$. There were no young cattle tested.

Table 3

Prevalence of Trypanosoma spp in cattle and goats in Year 2015

\begin{tabular}{|c|c|c|c|c|c|c|c|c|c|c|c|}
\hline \multirow{2}{*}{\multicolumn{2}{|c|}{ Category }} & \multicolumn{4}{|c|}{ Prevalence (\%) in Cattle } & \multicolumn{6}{|c|}{ Prevalence (\%) in Goats } \\
\hline & & No.* & $\begin{array}{l}T . \\
\text { congolense }\end{array}$ & $\begin{array}{l}\text { T. } \\
\text { brucei }\end{array}$ & $\begin{array}{l}T . \\
\text { vivax }\end{array}$ & $\mathrm{P \#}$ & No.* & $\begin{array}{l}T . \\
\text { congolense }\end{array}$ & $\begin{array}{l}T . \\
\text { brucei }\end{array}$ & $\begin{array}{l}T . \\
\text { vivax }\end{array}$ & P\# \\
\hline \multicolumn{12}{|c|}{ Location } \\
\hline & Kashaka & - & - & - & - & - & 50 & 12.0 & 16.0 & 34.0 & 50.0 \\
\hline & Kirugu & - & - & - & - & - & 89 & 10.1 & 19.1 & 6.7 & 32.6 \\
\hline & Kisenyi & - & - & - & - & - & 41 & 31.7 & 22.0 & 19.5 & 43.9 \\
\hline & Rwenshama & - & - & - & - & - & 139 & 18.7 & 18.7 & 7.2 & 33.1 \\
\hline & Nyakatonzi & - & 12 & 17.5 & 23.0 & 11.1 & 38.9 & - & - & - & - \\
\hline \multirow[t]{2}{*}{ Sex } & Male & 23 & 17.4 & 39.1 & 0.0 & 47.8 & 57 & 10.5 & 26.3 & 3.5 & 33.3 \\
\hline & Female & 103 & 17.5 & 19.4 & 13.6 & 36.9 & 262 & 18.3 & 17.2 & 14.9 & 37.8 \\
\hline \multirow[t]{3}{*}{ Age } & Adult & 70 & 21.4 & 22.9 & 11.4 & 44.3 & 186 & 17.2 & 17.2 & 12.4 & 34.4 \\
\hline & Sub-adult & 56 & 12.5 & 23.2 & 10.7 & 32.1 & 131 & 16.8 & 20.6 & 13.7 & 40.5 \\
\hline & Young & - & - & - & - & - & 2 & 0.0 & 50.0 & 0.0 & 50.0 \\
\hline
\end{tabular}


A total of 250 blood samples were collected from cattle in May 2017. No blood samples were collected from goats during this time. The Packed Cell Volume (PCV) ranged from $17-40 \%$. The average PCV of the sampled cattle was $29.1 \%$. The mean PCV value for infected cattle $(n=89)$ was $29 \%$ while the mean PCV value for the non-infected cattle $(n=149)$ was $29.1 \%$.

Approximately $71.8 \%(n=171)$ of cattle sampled had PCV of less than $32 \%$ (anemic) while the rest of the cattle had PCV of $\geq$ $32 \%$ (non-anemic). There were no significant differences between the mean PCV of infected and non-infected cattle at $5 \%$ level of significance $(p>0.892)$.

The overall prevalence of Trypanosoma spp was 38\%, $1.2 \%, 1.2 \%$ and $2.4 \%$ for PCR, thin smear, thick smear and buffy coat diagnostic techniques, respectively. There was a statistically significant difference in the trypanosome prevalence detection by the different techniques $(p=0.000)$. Post-hoc analysis revealed that detection by PCR was significantly higher than the other techniques $(p=0.000)$. Based on PCR, the prevalence for T. congolense $(\mathrm{n}=80,32.4 \%), T$. vivax $(\mathrm{n}=17,6.8 \%)$ and T. brucei $(\mathrm{n}$ $=16,6.4 \%)$ were statistically different $(F=12.76 ; p<0.002)$. Post hoc analysis showed that $T$. congolense was significantly more prevalent than T. brucei and T. vivax. A co-infection of T. brucei and T. congolense was most encountered in the study area $(n=19 ; 7.4 \%)$. Only $3.2 \%(n=8)$ of the cattle were co-infected with all the three Trypanosome species. There was no mixed infection of $T$. brucei and T. vivax recorded in the study area for this period.

By individual location, the prevalence of trypanosomes was high in Muhokya ( $56.3 \% ; n=27)$ followed by Lake Katwe $(42.9 \%$, $n=15)$ and less prevalent in Kahendero $(24.1 \%, n=13)$. The prevalence of $T$. congolense was highest in all the sub-counties of study followed by T. vivax (except in Nyakatonzi) while T. brucei was least prevalent (Table 4). There was a significant difference in prevalence of trypanosomes by location $(p=0.039)$. Using the Post-hoc analysis, Muhokya was found to have a significantly higher prevalence than Kahendero $(p=0.001)$. There was no significant difference in prevalence of Trypanosoma spp between Muhokya, Karusandara, Lake Katwe and Nyakatonzi $(p>0.05)$.

Comparing sex, the prevalence of Trypanosoma spp. was not significantly different between female cattle $(36.8 \%, \mathrm{n}=84 / 228)$ and male cattle $(27.3 \%, \mathrm{n}=6 / 22)(p=0.513)$ (Table 4). The overall prevalence of Trypanosoma spp was higher in adult cattle $(37.1 \%, \mathrm{n}=75)$ than in young ones $(31.3 \%, \mathrm{n}=15)$ though this was not statistically significant (Independent $\mathrm{T}$ - test, $p=0.062)$. The prevalence of Trypanosoma spp was high in local breeds $(38.1 \%, n=69)$ followed by cross breeds $(37.1 \%, n=23)$ and least prevalent in Friesian breeds $(14.3 \%, n=1)$. There was no case of $T$. brucei recorded in the Friesian breeds. In as much as the prevalence differed among the cattle breeds, there was a strong association $(F=0.736, p=0.001)$. 
Table 4

Prevalence of Trypanosoma spp in cattle in May 2017

\begin{tabular}{|c|c|c|c|c|c|c|}
\hline \multirow[t]{2}{*}{ Category } & & \multicolumn{3}{|c|}{ Prevalence (\%) } & \multirow[b]{2}{*}{ T. vivax } & \multirow[b]{2}{*}{ Overall* } \\
\hline & & No.\# & T. congolense & T. brucei & & \\
\hline \multirow[t]{5}{*}{ Sub-county } & Kahendero & 54 & 18.5 & 3.7 & 5.6 & 24.1 \\
\hline & Karusandara & 35 & 37.1 & 8.6 & 11.4 & 37.1 \\
\hline & L. Katwe & 35 & 37.1 & 5.7 & 8.6 & 42.9 \\
\hline & Muhokya & 48 & 47.9 & 4.2 & 6.3 & 56.3 \\
\hline & Nyakatonzi & 78 & 28.2 & 10.3 & 5.2 & 34.6 \\
\hline \multirow[t]{2}{*}{ Sex } & Male & 22 & 27.3 & 4.5 & 4.5 & 27.3 \\
\hline & Female & 228 & 32.9 & 7 & 7 & 36.8 \\
\hline \multirow[t]{3}{*}{ Age } & Young & 48 & 29.2 & 4.1 & 8.2 & 31.3 \\
\hline & Adult & 202 & 33.2 & 7.4 & 6.4 & 37.1 \\
\hline & Local & 181 & 32.6 & 7.7 & 6.6 & 38.1 \\
\hline \multirow[t]{2}{*}{ Breed } & Cross & 62 & 33.9 & 4.8 & 6.5 & 37.1 \\
\hline & Friesian & 7 & 14.3 & 0 & 14.3 & 14.3 \\
\hline
\end{tabular}

\section{\# - Number of cattle sampled per category; *Overall prevalence}

\section{Discussion}

\section{Species of Tsetse flies in and around QENP}

Glossina fuscipes, G. pallidipes and G. brevipalpis are sub-species of tsetse flies previously reported to exist in Uganda $(4,8)$ $(15,16)$. The current study showed the presence of only two types of tsetse fly species, G. fuscipes and G. pallidipes in rangelands within and around QENP ecosystem and surroundings. Similar results have been reported in Uganda by Albert (4) and Waiswa et al. (17) in the Lake Victoria basin and eastern Uganda, respectively. Glossina pallidipes was the most predominantly caught species in communities around Queen Elizabeth national park, south western Uganda. The results are different from those of previous studies in Uganda $(4,17)$ and Ngonyoka et al $(18)$ in Tanzania that all showed G. fuscipes as the dominant species.

Glossina pallidipes was predominantly found in the thickets and shrubs vegetation. The current study area was generally a savannah land dominated with invasive species of thickets and shrubs. Species, for example, Acacia spp, Eurphobia sp and Lantana camara among others, with small trees less than 3 meters above the ground, were the dominant species. This probably explains the presence of high numbers of G. pallidipes in the study area as such land cover provides unique ecological conditions ideal for survival and infestation of $G$. pallidipes $(3,4,16,19)$. The thickets and shrubs had the highest number of tsetse fly catches. The results agree with literature which suggests that $G$. pallidipes inhabits woodland savannas and thickets $(16,20,21)$. Tsetse flies are very sensitive to changes in the environment and the ecology of an area. Factors such as temperature, humidity and vegetation cover are important in provision of shade and maintenance of suitable microclimate and a habitat for hosts of tsetse flies $(4,19,20,22)$.

Sex ratio of caught tsetse flies indicated that higher numbers of females were recorded during the study. Similar results have been reported elsewhere $(1,4,19)$. High number of females present in the study area could result in future high population density of tsetse flies and ultimately infection rate (1). The high proportion of females in the current study can probably be 
attributed to the fact that females live longer than males (mean female fly life span is 8 weeks, but only 4 weeks for the males). Therefore, more females could be trapped (1).

There was an existence of more biting flies than tsetse flies in each trap. This is in agreement with previous literature which suggest that parts of south west and mid central Uganda have lower populations of tsetse flies than other biting flies (4). Presence of biting flies could pose a threat to livestock production since biting flies such as Stomoxys and Tabanids among others have been associated with mechanical transmission of some livestock diseases such as AAT $(23,24)$. Severe biting by these flies may be a nuisance to animals resulting in physical discomfort, wounds, reduced weight and milk production in livestock (23-25).

Different types of traps have been designed to catch different species of tsetse flies and these traps have been reported to have varying effectiveness in trapping different tsetse fly species (26-28). In this study, two different traps (Biconical and F3) were used in the capture of tsetse flies within and around QENP and their efficiency was determined. Generally, Biconical traps (BT) were more effective in trapping tsetse flies in the study area than F3 traps regardless of the tsetse fly species. Higher number of tsetse flies captured by biconical traps in this study could probably be explained by nearly twice the numbers of biconical traps deployed as compared to the F3 traps. Overall, 5003 tsetse flies were captured in the study with the calculated TFTD of 20.6 which comparable to that reported by Apaatah (1) and Salekwa et al. (21). However, it is higher than that previously reported by Albert (4).

\section{Prevalence of Trypanosoma spp in goats and cattle}

The prevalence of Trypanosoma spp in both cattle (37\%) and goats (38.9\%) for samples collected in 2015 based on PCR was higher than that reported by other studies in the same animal species in Uganda, Nigeria and Zambia $(2,5,13,14,23)$. In addition, the overall prevalence of Trypanosoma spp cattle (38\%) samples collected in 2017, based on PCR results was higher than what has been reported in previous studies in the country. For instance, the prevalence was $7.6 \%$ in Kasese, Rakai and Jinja districts of Uganda (14), 2.4\% in Mbarara district, western Uganda (5) and 15.3\% in Tororo district, eastern Uganda (11). This prevalence is also higher than in studies carried out in other tsetse fly endemic countries in Africa $(1,2,25,29,30)$. However, some studies have reported almost similar prevalence of Trypanosoma spp in cattle. For example, reports in Zambia and Ivory Coast showed prevalence of $33.5 \%$ and $22.31 \%$ in cattle in Zambia (2) and Ivory Coast (30) respectively. The higher prevalence of trypanosomes in this study could probably be explained by the close proximity of the study sites to the QENP savannah grasslands that hosts various wildlife species that are possible reservoirs of Trypanosoma spp. Wildlife has previously been reported to be important reservoir and maintenance hosts of Trypanosoma spp $(5,8,31)$. In addition, the difference in prevalence observed in Uganda could be due to variations in different geo-ecological zones and time of year for sampling $(5,14,24,30)$. The type of husbandry practices such as communal grazing, free range grazing and climatic variations across different geographical regions can influence the survival of both the parasites and vectors. Fishing communities within QENP keep goats that directly and indirectly interact with wildlife species. In addition, it is not uncommon to find wildlife interacting with cattle around QENP especially in communities that neighbour the national park.

The prevalence of trypanosomes was higher in cattle than in goats, for samples collected in 2015. The chances of an animal being infected with trypanosomes vary with the geographical location, the rate at which the host is being fed on by the infected tsetse fly $(2,14)$, the detection of carbon dioxide emitted by potential vertebrate host, the short-range visual and olfactory stimuli by a tsetse, and the behavior of a particular host (2). Cattle have larger body sizes compared to goats and therefore are most likely to emit more odor (carbon dioxide) and therefore likely to attract more tsetse flies than goats $(2,14)$.

The study confirmed presence of T. congolense, T. vivax and T. brucei in both goats and cattle for years 2015 and 2017 . T. vivax was the least prevalent of all the species. This is contrary to other studies that have reported T. vivax as the most predominant species in the endemic parts of Uganda $(5,11,14,24)$. However, the results are consistent with studies in Zambia $(2,32,33)$, Nigeria $(25,34)$, Ghana (1) and some parts of Uganda (35) where T. congolense was reported to be the most prevalent species. The high prevalence of $T$. congolense could be attributed to the complementary roles played by major 
cyclic vectors like G. pallidipes. In addition, T. congolense species is associated with very high pathogenic levels in animals which can lead into higher parasitaemia hence easily detected in the field.

Mixed infections for all the species for T. brucei and T. vivax was only in cattle and goats sampled in 2015. In both years, there was mixed infections for all species of Trypanosoma in both cattle and goats though it was less prevalent in cattle samples of 2017. Trypanosoma brucei and T. congolense mixed infections was most prevalent for both years in all animals. Presence of mixed infection was consistent with the findings by Apaatah(1), Kouadio et al. (30) and Samdi (25).

For samples collected in 2015, there was no major variations in the prevalence of trypanosome infections in all the study sites. The results were consistent with those reported in a previous report (1). This could suggest that climatic and ecological conditions which influence tsetse fly distribution in these communities sampled may be homogeneous. However, for samples collected in 2017, there was a statistically significant difference in the prevalence of trypanosome species by location with Muhokya and Lake Katwe, that are closely bordering the national park, having higher prevalence compared to other sites. The results are consistent with studies elsewhere which showed that prevalence of trypanosomes are higher in sites that are in close proximity to wildlife areas $(14,30)$. The pastoralists around QENP practice similar traditional husbandry management practices such as communal grazing and sometimes graze near or inside the national park. They expose their animals to tsetse flies that are more common inside than outside the national park. The occurrence of trypanosomes causing AAT directly corresponds to the availability of the vector (especially tsetse fly) $(1,26)$.

Even though the prevalence of Trypanosoma species was slightly higher in adult animals than in young ones, and in females than males, there was no statistically significant difference between age and sex prevalence in this study. This was consistent with the studies conducted in Ghana and Nigeria $(13,36)$. This may be probably due to fact that sex of the animal does not influence their susceptibility to trypanosome infections or being bitten by a tsetse fly. Farmers within the study area tend to sell off male animals to complement household income and therefore the numbers at sampling may be much less than females.

The survey for tsetse fly distribution was not conducted widely nor done in both the years to allow for comparison. The infection rates of tsetse flies captured was not investigated as well as season variations in the tsetse fly abundance. The prevalence of T. brucei and T. congolense was high for samples collected in 2015 and 2017 respectively. This may be a true picture of prevalence since we tested the samples using same method of PCR. In this study, there was a time lag between sample collection and direct examination in the laboratory which could easily affect that we got. In addition, we didn't sample same farms for cattle in year 2015 and 2017. However, these were the same areas in some instances.

\section{Conclusions}

This study showed that QENP ecosystem and the surroundings areas are highly infested by tsetse flies of mainly G. pallidipes and G. fuscipes sub-species. Glossina fuscipes sub-species were also recorded in Nyakatonzi community. Both goats and cattle were highly infected with trypanosome species. Therefore, there is need to intensify tsetse fly and trypanosomiasis control effort and measures in the communities around Queen Elizabeth National Park. The high proportion of goats infected with trypanosomes points to their role as domestic livestock reservoirs in the epidemiology of the disease in livestock. This implies that goats should also be given attention as much as cattle in the control and prevention of AAT. The presence of $T$. brucei sub-species in livestock that share rangelands with wildlife and humans pose a significant public health threat since T. brucei may cause Nagana that disrupts livestock production. There is need for urgent attention from all relevant stakeholders to intensify wide vector and disease management of tsetse fly infestation and Nagana in communities bordering the national park in order to safeguard livelihoods.

\section{Methods}

\section{Study area}


The study was conducted in selected communities within and around QENP, southwestern Uganda. It is adjacent to the Democratic Republic of Congo (DRC) and is situated at the equator $\left(00^{\circ} 12^{\prime} \mathrm{S} 30^{\circ} 00^{\prime} \mathrm{E}\right)$ within the western Albertine Rift Valley. The park occupies an estimated area of $1,978 \mathrm{~km}^{2}$ and covers part of the Greater Virunga landscape, which comprises of multiple wildlife reserves that include Kyambura Game Reserve, Kibale Forest National Park, Kigezi Game Reserve all in Uganda and Virunga National Park in DRC among others (37). QENP further extends from Lake George in the north-east to L. Edward to the south-west and includes Kazinga channel connecting the two lakes, a range of wetlands and crater lakes (37). The study area is situated in a semi-arid area with mainly two dry and two wet seasons annually. Dry seasons are estimated to be from December to February and June to August while wet seasons are March to May and September to November. The mean annual rainfall varies within the park with a mean of 1,200 mm near the Rift Valley wall and $500 \mathrm{~mm}$ around Lakes George and Edward (37). The area comprises of a diverse range of vegetation types (Fig. 5) which includes open grasslands, grassland with thickets, thickets and shrubs, forests, wetlands, riverine vegetation species and about $250 \mathrm{~km}$ of lakeshore (37).

A cross-sectional study was conducted in 12 selected communities which extended in three districts of Kasese, Rubirizi and Rukungiri all bordering the QENP. Some of the communities lie within the national park in about 11 fishing enclaves carrying out mainly fishing activities but keep livestock that they graze illegal in the national park. Other communities that border the national park practice crop growing and livestock keeping (pastoralism). A minimal entomological survey was conducted to determine tsetse fly distribution in the study area (Fig. 5) and determine occurrence of trypanosomiasis. A map was developed by our team to show the distribution of flies and trypanosomes. The information was collected to provide baseline data for decision makers after an outcry from communities that border the national park.

\section{Collection Of Tsetse Fly Samples (entomological Survey)}

This minimal entomological survey was conducted in May 2017 which coincides with the rainy season in the study area. During the survey, biconical $(n=56)$ and F3 traps $(n=23)$ were set up at an interval of about 200 metres to 250 metres apart in vegetations close to rivers, streams and in savanna rangelands. The sampled points were geo-referenced. Traps were set in selected communities within and around QENP and left at each site for about 72 hours. The trapped tsetse flies were then retrieved, preserved in $70 \%$ alcohol and then transferred to the College of Natural Sciences at Makerere University for identification and storage. Tsetse fly species were identified based on the morphological characteristics as previously described by Leak et al. Leak, Ejigu (26). Other biting flies were also identified and separated according to their morphological characteristics such as colour, size, proboscis and wing structure (26).

Vegetation types in the study area were observed, categorized and recorded around the trap sites. They included: a) Thickets \& Shrubs characterized by Acacia trees, Eurphobia spp and Lantana camara among others, with small trees less than 3 metres above the ground; b) Open Savannah grass land characterized by grass up to height of 1-5 metres, very few shrubs and entirely open with limited shade; c) Marshy Riverine woodland characterized by riverine vegetation and woodland/ forest in water logged area especially along River Nyamugasani; and d) Grassland \& thickets - these were mainly thickets localized in open grassland.

\section{Collection And Processing Of Blood Samples}

The study utilized blood samples from cattle $(n=126)$ and goats $(n=319)$ collected and archived in June 2015. In addition, the study utilized blood samples collected from only cattle $(n=250)$ between April to May 2017 upon request from farmers who had reported problem of tsetse flies affecting their animals. Simple random sampling was used to select the villages and farms to be sampled. Simple random sampling technique was used to determine the goats and cattle to be sampled in each pastoralist community while in communities with very small livestock numbers less than ten, all the cattle and goats present were sampled. Specifically, blood samples from cattle and goats were collected from the jugular vein after restraining the animal. The samples were collected by veterinarians using a protocol approved by the ethics committee at the College of

Page $10 / 17$ 
Veterinary Medicine, Animal Resources and Biosecurity (COVAB), Makerere University. Approximately 5 mls of whole blood were collected and stored in a vacutainer tube containing Ethylenediaminetetraacetic acid (EDTA). The vacutainer tubes with whole blood were placed in a cool box containing ice packs and transported to the Research Center for Tropical Diseases and Vector Control laboratory at COVAB. All animals were then given back to the owner without further manipulation. The blood samples were aliquoted into $2 \mathrm{ml}$ serum tubes for storage at $-30^{\circ} \mathrm{C}$ until time for analysis. For blood samples collected from cattle in 2017, Giemsa stained thick and thin smears were made and processed while still in the field as described by Swai et al. (38). In the field laboratory, capillary tubes were placed in a microhematocrit centrifuge and centrifuged at 12,000 revolutions per minute for 5 minutes. The packed cell volume (PCV) was measured using a microhematocrit reader and then recorded in a data sheet with corresponding animal information. The readings were expressed as a percentage of packed red cells to the total volume of whole blood. Animals with PCV less than 32 were considered to be anaemic (1). The contents of the buffy coat region were observed under a light microscope for trypanosome parasites.

\section{Deoxyribonucleic Acid (dna) Extraction And Amplification}

Stored whole blood was thawed and a $200 \mu$ of whole blood was pipetted into labelled sterile $1.5 \mathrm{ml}$ Eppendorf tubes. DNA was extracted from the whole blood samples using Qiagen blood mini-kit (Qiagen, Duesseldorf, Germany) following the manufacturers instructions with a few modifications where necessary. The eluted DNA (50 $\mu \mathrm{l})$ was stored at $-20^{\circ} \mathrm{C}$ or used directly using conventional PCR.

Amplification of trypanosome DNA was performed in a total reaction volume of $12.5 \mu \mathrm{l} \mathrm{PCR}$ reaction mixture containing $0.25 \mu \mathrm{l}$ of polymerase enzyme (KOD FX Neo, Toyobo, Japan), $2.5 \mu \mathrm{l}$ of PCR water, $1.25 \mu \mathrm{l}$ of Deoxynucleoside triphosphates, $6.25 \mu \mathrm{l}$ of buffer, $2 \mu \mathrm{l}$ of template and $125 \mu \mathrm{l}$ of each of the primers (ITS1 CF: 5'CCGGAAGTTCACCGATATTG-3' and ITS1 BR 5'TTGCTGCGTTCTTCAACGAA-3') designed to amplify internal transcribed spacer ITS1 of different trypanosomes ribosomal deoxyribonucleic acid (rDNA) (8). ITS1 TF/BR primers, priming the ITSI of rDNA of different Trypanosoma species were expected to generate bands in the regions of 700,480 and 250 base pairs that correspond to T. congolense, T. brucei s.l, and T. vivax respectively. PCR was carried out in a SimpliAmp® ThermoCycler (Thermofisher, USA) at the following cycling conditions; denaturation step at $94^{\circ} \mathrm{C}$ for 5 minutes, 35 cycles of denaturation at $94^{\circ} \mathrm{C}$ for 1 minute each cycle, annealing at $60{ }^{\circ} \mathrm{C}$ for 1 minute, extension at $72{ }^{\circ} \mathrm{C}$ for 1 minute and a final elongation step at $72{ }^{\circ} \mathrm{C}$ for 5 minutes. PCR products were electrophoresed in $1.5 \%$ agarose gel and stained with ethidium bromide. The gels were visualized on an ultraviolet trans illuminator following the methods described previously (5).

\section{Data Analysis}

Data from laboratory analysis and entomological survey was entered into Microsoft excel spread sheets, cleaned and exported to Statistical Package for Social Scientists (SPSS) (version 20.0) to generate descriptive statistics. Descriptive results were summarized using frequencies and percentages and presented as charts and tables. Spatial analysis was done using Arc GIS version 10.2 to generate tsetse fly distribution maps. The maps developed are our own. The apparent density, which is relative to the type of sampling trap used, was expressed as the average number of tsetse flies caught per trap used per day (FTD) (26). The apparent density was calculated for each trap used (T) and the number of days (D) for which the that particular trap was operational (17). Therefore, FTD = F/TxD. If the trap was destroyed or not operation for some reason, then the trap-day was excluded. Post Hoc Analysis was conducted to find out differences in tsetse fly caught per vegetation type. Independent sample T-test was done to analyse the difference in prevalence of trypanosomes between the sampled cattle and goats in communities around QENP. Analysis of Variance (ANOVA) was used to test the difference in prevalence of trypanosomes among the study communities, cattle breeds, trypanosome species and vegetation type. The analysis was done at $95 \%$ confidence interval and $5 \%$ level of significance. All variables in inferential analysis with P-values less than 0.05 were considered significant.

\section{Abbreviations}


AAT: African Animal Trypanosomiasis; ANOVA - Analysis of Variance; BT-Biconical traps; COVAB - College of Veterinary medicine Animal Resources and Biosecurity; DNA- Deoxyribonucleic Acid; EDTA - Ethylenediaminetetraacetic acid; FTP-Flies per trap per day; PCR-Polymerase Chain Reaction; PCV-Packed Cell Volume; QENP-Queen Elizabeth National Park; rDNA ribosomal deoxyribonucleic acid;

\section{Declarations}

\section{Ethics approval and consent to participate}

The study was submitted to Makerere University's COVAB ethics review board for approval. Ethical clearance approval for human sample collection was provided by the College of Health Sciences, School of Biomedical Sciences, Higher Degrees Research and Ethics Committee (SBS-HDREC) with award file number (SBS-191). A written informed consent was obtained from each of the respondents to participate. Goats and cattle were neither euthanized nor treated after sample collection. All insect samples were kept in sample tubes for future analysis if and when needed.

\section{Consent to publish}

Not applicable

\section{Availability of data and materials}

All the data generated or analyzed during this study are included in the published article. All the animals from which the blood samples were collected were returned back to the farmers.

\section{Competing interests}

The authors declare that they have no competing interests.

\section{Funding}

All the work was funded by the International Research Development Center (IDRC) - Canada Ecohealth Chair Grant (Grant No. 107345-001) to IBR. The funder did not have any role in the study design, collection, analysis and the interpretation of data and in drafting the manuscript.

\section{Authors' contributions}

AA, JB and IBR conceived the study; AA, SJK, IBR and JS collected tsetse fly and blood samples from the field. AAMK, JB, JS and PV conducted laboratory data analysis. JM, DM, PB and IBR were responsible for data analysis and drafting of the manuscript; DM and IBR were overall coordinate of manuscript writing. All authors have read, edited and approved the submitted version of the manuscript.

\section{Acknowledgments}

We would like to thank the Kasese and Rubirizi District Veterinary Offices for the support in collection of tsetse fly and blood samples. In addition, we thank Hellen Kiconco, Yona Kajuna, Henry Mugaya, Joseph Masinde, Ronah Asasira, and Patrick Abila for support in the field during collection of samples.

\section{References}


1. Apaatah F. Tryapnasome prevalence in pigs and tsetse flies from Jomoro District in the Western region of Ghana.: University of Ghana; 2014.

2. Simukoko H, Marcotty T, Phiri I, Geysen D, Vercruysse J, Van den Bossche P. The comparative role of cattle, goats and pigs in the epidemiology of livestock trypanosomiasis on the plateau of eastern Zambia. Veterinary parasitology. 2007;147(3-4):231-8.

3. Firesbhat A, Desalegn C. Epidemiology and Impacts of Trypanosomiasis in Cattle. European Journal of Applied Science. 2015;7(5):220-5.

4. Albert M, Wardrop NA, Atkinson PM, Torr SJ, Welburn SC. Tsetse Fly (G.f. fuscipes) Distribution in the Lake Victoria Basin of Uganda. PLoS Neglected Tropical Diseases 2015;9(4).

5. Alingu RA, Muhanguzi D, MacLeod E, Waiswa C, Fyfe J. Bovine trypanosome species prevalence and farmers' trypanosomiasis control methods in south-western Uganda. Journal of the South African Veterinary Association. 2014;85(1).

6. Alam U, Hyseni C, Symula RE, Brelsfoard C, Wu Y, Kruglov O, et al. Implications of Microfauna-Host Interactions for Trypanosome Transmission Dynamics in Uganda. Appl Environ Microbiol. 2012;78(13):4627.

7. Jittapalapong S, Pinyopanuwat N, Inpankaew T, Sangvaranond A, Phasuk C, Chimnoi W, et al. Prevalence of Trypanosoma evansi Infection Causing Abortion in Dairy Cows in Central Thailand. Kasetsart Journal - Natural Science. 2009;43:53-7.

8. Steverding D. The history of African trypanosomiasis. Parasit Vectors. 2008;1(1):3.

9. Wamwiri FN, Changasi RE. Tsetse Flies (Glossina) as Vectors of Human African Trypanosomiasis: A Review. Biomed Res Int. 2016;2016:6201350.

10. Adamu UO, Haruna MK, Ovbagbedia RP, Bizi R, Benjamin W, Malala UA, et al. Control of African Trypanosomiasis in Nigeria: Time to Strengthening Integrated Approaches (A Review). International Journal of Animal Veterinary Advances. 2011;3(3):138-43.

11. Muhanguzi D, Picozzi K, Hattendorf J, Thrusfield M, Kabasa JD, Waiswa C, et al. The burden and spatial distribution of bovine African trypanosomes in small holder crop-livestock production systems in Tororo District, south-eastern Uganda. Parasites Vectors. 2014;7(1):603.

12. Gumaa M, Abusalab S, Omer M, Salih D, Mulla S, Omer E, et al. A two year study on bovine trypanosomosis in Kassala State, Eastern Sudan (2007-2008). International Research Journal of Agricultural Science. 2011;1:96-7.

13. Ezebuiro OGC, Abenga JN, Ekejindu GOC. The Prevalence Of Trypanosome Infection In Trade Cattle, Goats And Sheep Slaughtered At The Kaduna Abattoir. African Journal of Clinical Experimental Microbiology. 2009;10(1):15-25.

14. Biryomumaisho S, Rwakishaya EK, Melville SE, Cailleau A, Lubega GW. Livestock trypanosomosis in Uganda: parasite heterogeneity and anaemia status of naturally infected cattle, goats and pigs. Parasitol Res. 2013;112(4):1443-50.

15. Berrang-Ford L, Garton K. Expert knowledge sourcing for public health surveillance: National tsetse mapping in Uganda. Soc Sci Med. 2013;91:246-55.

16. Cecchi G, Mattioli RC, Slingenbergh J, de la Rocque S. Land cover and tsetse fly distributions in sub-Saharan Africa. Med Vet Entomol. 2008;22(4):364-73.

17. Waiswa C, Picozzi K, Katunguka-Rwakishaya E, Olaho-Mukani W, Musoke RA, Welburn SC. Glossina fuscipes fuscipes in the trypanosomiasis endemic areas of south eastern Uganda: apparent density, trypanosome infection rates and host feeding preferences. Acta Trop. 2006;99(1):23-9.

18. Ngonyoka A, Gwakisa PS, Estes AB, Nnko HJ, Hudson PJ, Cattadori IM. Variation of tsetse fly abundance in relation to habitat and host presence in the Maasai Steppe, Tanzania. J Vector Ecol. 2017;42(1):34-43.

19. Desta M. The study on tsetse fly (Glossina species) and their role in the trypanosome infection rate in Birbir valley, Baro Akobo River system, western Ethiopia. 2013;Vol. 5.

20. Gondwe N, Marcotty T, Vanwambeke SO, De Pus C, Mulumba M, Van den Bossche P. Distribution and density of tsetse flies (Glossinidae: Diptera) at the game/people/livestock interface of the Nkhotakota Game Reserve human sleeping 
sickness focus in Malawi. Ecohealth. 2009;6(2):260-5.

21. Salekwa LP, Nnko H, Ngonyoka A, Estes A, Agaba M, Gwakisa P. Relative abundance of tsetse fly species and their infection rates in simanjiro, Northern Tanzania. Livestock Research for Rural Development. 2014;26.

22. Cecchi G, Paone M, Argilés Herrero R, Vreysen MJ, Mattioli RC. Developing a continental atlas of the distribution and trypanosomal infection of tsetse flies (Glossina species). Parasit Vectors. 2015;8:284.

23. Hamill L, Picozzi K, Fyfe J, von Wissmann B, Wastling S, Wardrop N, et al. Evaluating the impact of targeting livestock for the prevention of human and animal trypanosomiasis, at village level, in districts newly affected with $\mathrm{T}$. b. rhodesiense in Uganda. Infect Dis Poverty. 2017;6(1):16-.

24. Muhanguzi D, Mugenyi A, Bigirwa G, Kamusiime M, Kitibwa A, Akurut GG, et al. African animal trypanosomiasis as a constraint to livestock health and production in Karamoja region: a detailed qualitative and quantitative assessment. BMC Vet Res. 2017;13(1):355.

25. Samdi SM, Fajinmi AO, Kalejaye JO, Wayo B, Haruna MK, Yarnap JE, et al. Prevalence of Trypanosomosis in Cattle at Slaughter in Kaduna Central Abattoir. Asian Journal of Animal Sciences. 2011;5:162-5.

26. Leak SG, Ejigu D, Vreysen MJ. Collection of entomological baseline data for tsetse area-wide integrated pest management programmes. Vienna: Joint FAO/IAEA Programme of NuclearTechniques in Food and Agriculture; 2008.

27. Malele II, Ouma JO, Nyingilili HS, Kitwika WA, Malulu DJ, Magwisha HB, et al. Comparative performance of traps in catching tsetse flies (Diptera: Glossinidae) in Tanzania. Onderstepoort J Vet Res. 2016;83(1):a1057.

28. Nagagi YP, Silayo RS, Kweka EJ. Advancements in bait technology to control Glossina swynnertoni Austen, the species of limited distribution in Kenya and Tanzania border: A review. J Vector Borne Dis. 2017;54(1):16-24.

29. Fajinmi AO, Faleke OO, Magaji AA, Daneji Al, Gweba M. Presence of Trypanosome Species and Determination of Anaemia in Trade Cattle at Sokoto Abattoir, Nigeria. Research Journal of Parasitology. 2011;6:31-42.

30. Kouadio I, Sokouri D, Koffi M, Konaté I, Ahouty B, Koffi A, et al. Molecular Characterization and Prevalence of Trypanosoma Species in Cattle from a Northern Livestock Area in Côte d'Ivoire. Open Journal of Veterinary Medicine. 2014;04:314-21.

31. Kalule G. Comparative study of Tsetse and Trypanosomosis control methods in Kasese District. Kampala: Makerere University; 2010.

32. Katakura K, Lubinga C, Chitambo H, Tada Y. Detection of Trypanosoma congolense and T. brucei subspecies in cattle in Zambia by polymerase chain reaction from blood collected on a filter paper. Parasitol Res. 1997;83(3):241-5.

33. Masumu J, Tshilenge G, Mbao V. Epidemiological aspects of bovine trypanosomosis in an endemic focus of eastern Zambia: The role of trypanosome strain variability in disease pattern. Onderstepoort Journal of Veterinary Research. 2012;79(2).

34. Majekodunmi AO, Fajinmi A, Dongkum C, Picozzi K, Thrusfield MV, Welburn SC. A longitudinal survey of African animal trypanosomiasis in domestic cattle on the Jos Plateau, Nigeria: prevalence, distribution and risk factors. Parasit Vectors. 2013;6(1):239.

35. Cox AP, Tosas O, Tilley A, Picozzi K, Coleman P, Hide G, et al. Constraints to estimating the prevalence of trypanosome infections in East African zebu cattle. Parasites Vectors. 2010;3(1):82.

36. Abenga J, Enwezor F, Lawani F, Osue H, Ikemereh E. Trypanosome prevalence in cattle in Lere area in Kaduna State, North central Nigeria. Revue d'elevage et de medecine veterinaire des pays tropicaux. 2004;57:45-8.

37. Moghari NM. A Survey of Queen Elizabeth National Park (QENP) Communities' Attitudes Toward Human-Lion Conflict and Lion Conservation: George Mason University; 2009.

38. Swai E, Kaaya J. A parasitological survey for bovine trypanosomosis in the livestockwildlife ecozone of Northern Tanzania. Veterinary World. 2012;5:459.

\section{Figures}




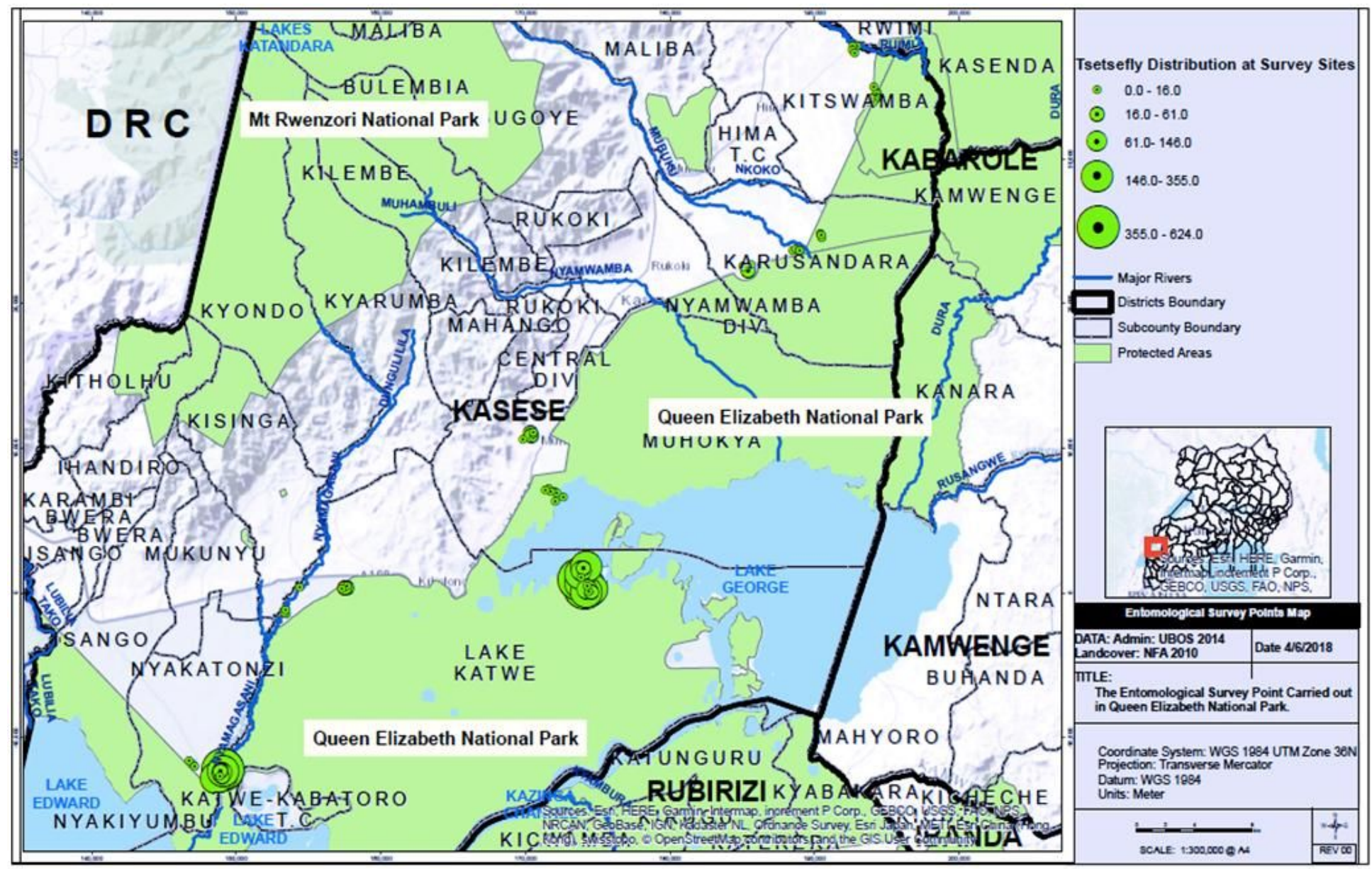

Figure 1

Land cover and entomological survey points for Tsetse flies in and around QENP, Uganda

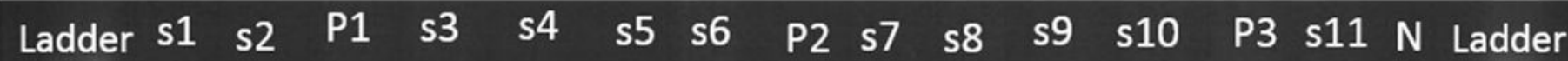

$700 \mathrm{bp}$

$480 \mathrm{bp}$

$250 \mathrm{bp}$

Figure 2 


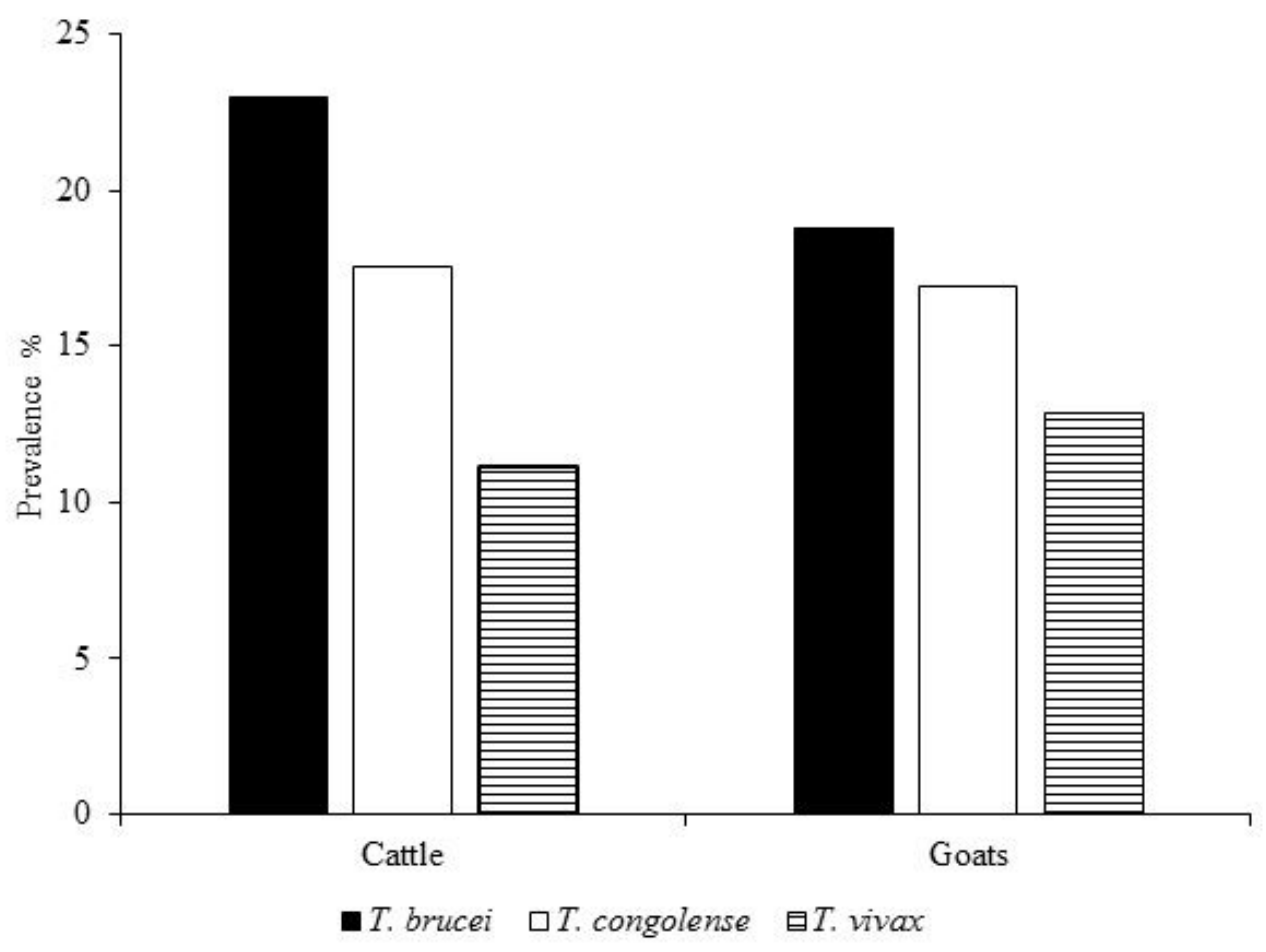

Figure 3

Uncropped Gel for the PCR products of the different Trypanosomes s1 to s11 correspond to test samples positive for trypanosomes and $\mathrm{N}$ indicates the Negative control while P1 is positive control for T. brucei, P2; positive control for T. vivax and $\mathrm{P} 3$ is positive control for T. congolensis . 700bp indicates T. congolensis, $480 \mathrm{bp}$ indicates T. brucei and $250 \mathrm{bp}$ represents T. vivax. Sample (s6) is positive for both T. congolensis and T. brucei. DNA ladder (100bp) was used as indicated on the gel above.

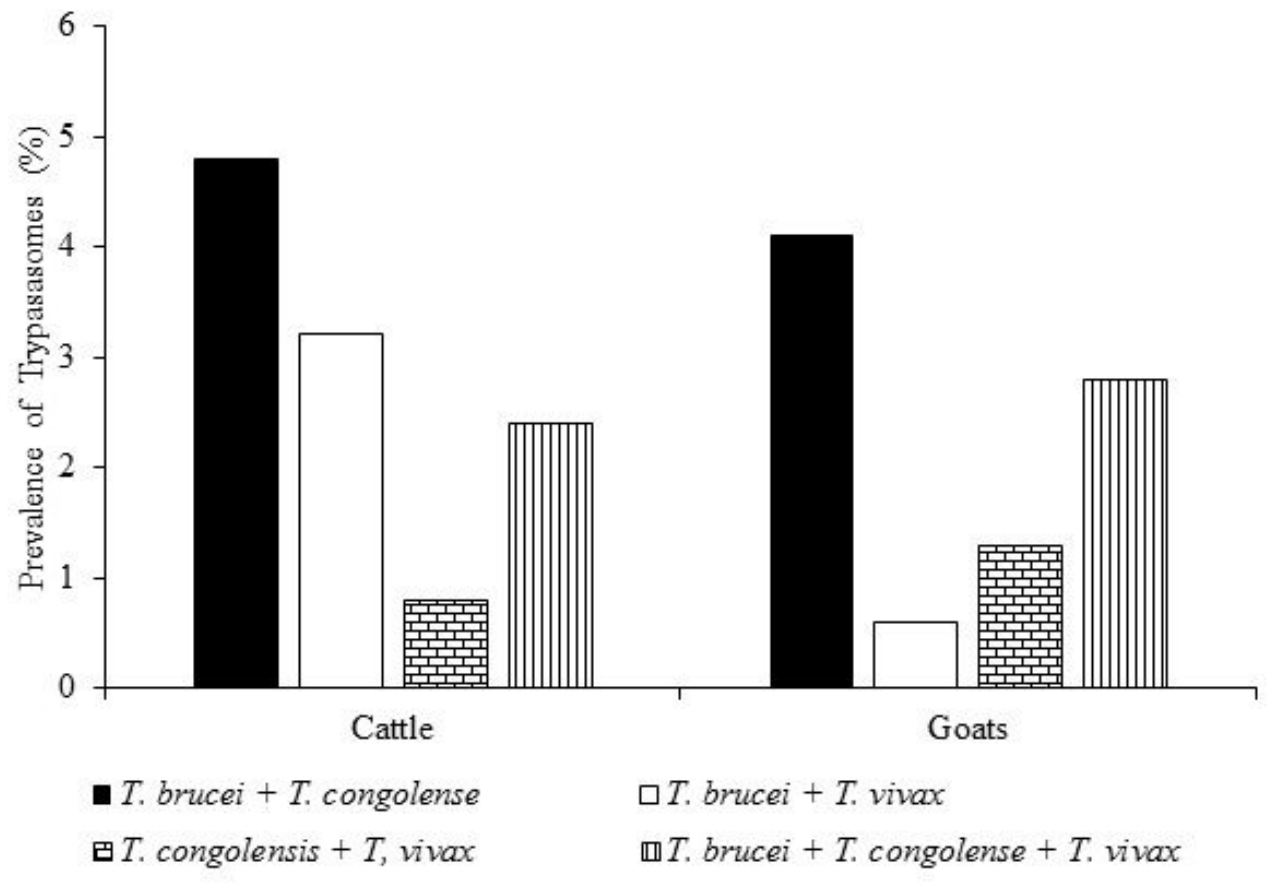

Figure 4

Prevalence of trypanosome mixed infections in cattle and goats in Year 2015 


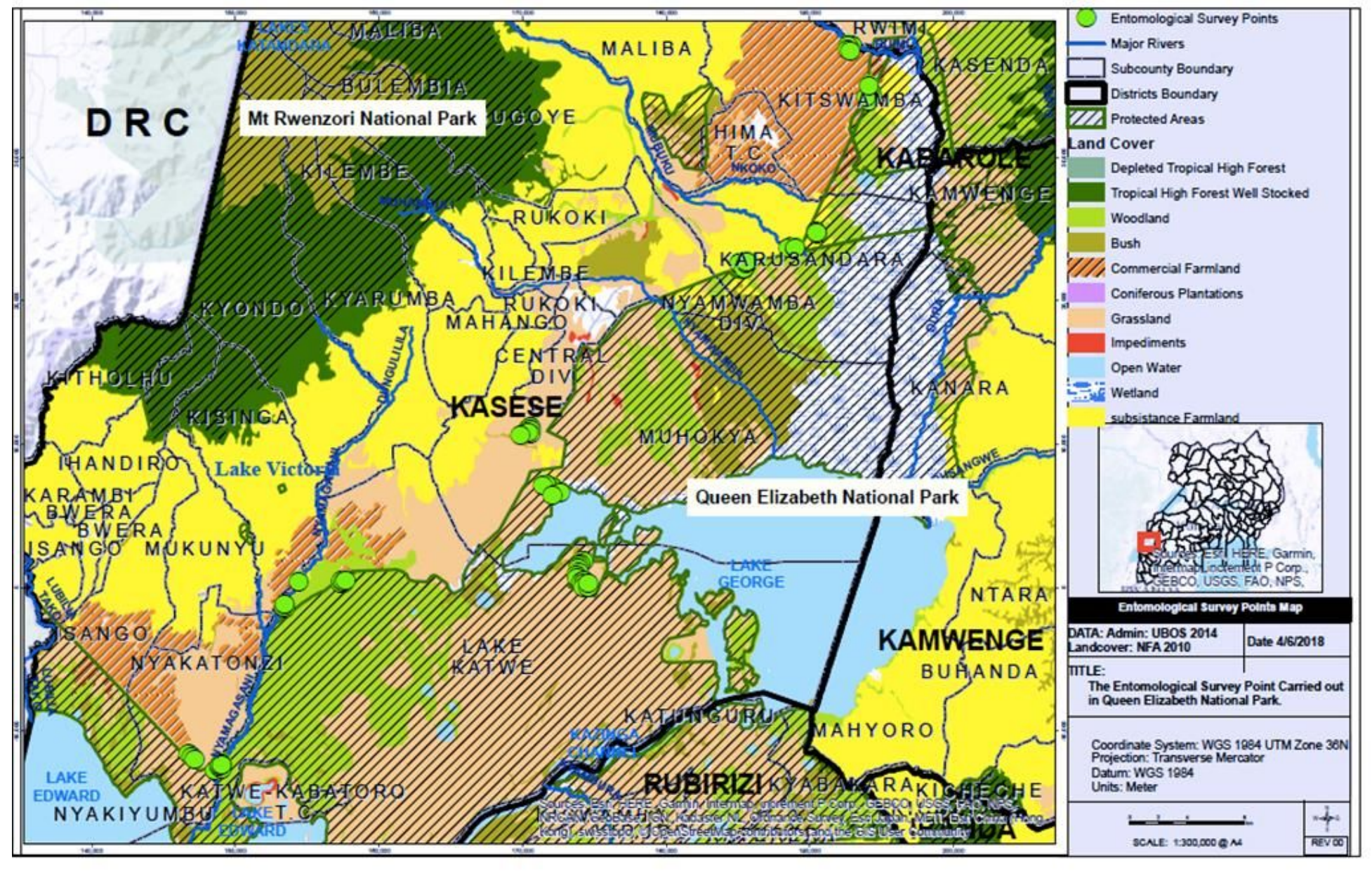

Figure 5

Prevalence of trypanosome mixed infections in cattle and goats in Year 2015 